\title{
Down-regulation of AR splice variants through XP01 suppression contributes to the inhibition of prostate cancer progression
}

\author{
Amro Aboukameel, Irfana Muqbil' ${ }^{2}$, Erkan Baloglư ${ }^{3}$, William Senapedis ${ }^{3}$, Yosef \\ Landesman ${ }^{3}$, Christian Argueta $^{3}$, Michael Kauffman ${ }^{3}$, Hua Chang ${ }^{3}$, Trinayan \\ Kashyap ${ }^{3}$, Sharon Shacham ${ }^{3}$, Jasper E. Neggers ${ }^{4}$, Dirk Daelemans ${ }^{4}$, Elisabeth I. \\ Heath $^{1}$ and Asfar S. Azmi ${ }^{1}$ \\ ${ }^{1}$ Wayne State University School of Medicine, Detroit, MI, USA \\ ${ }^{2}$ University of Detroit Mercy, Detroit, MI, USA \\ ${ }^{3}$ Karyopharm Therapeutics Inc, Newton, MA, USA \\ ${ }^{4} \mathrm{KU}$ Leuven Department of Microbiology and Immunology, Laboratory of Virology and Chemotherapy, Rega Institute for \\ Medical Research, Herestraat, Belgium \\ Correspondence to: Elisabeth I. Heath, email: heathe@karmanos.org \\ Asfar S. Azmi, email: azmia@karmanos.org
}

Keywords: metastatic prostate cancer; AR SPLICE variant; nuclear export; CRM 1; SINE

Received: July 12, $2018 \quad$ Accepted: October 06, $2018 \quad$ Published: October 19, 2018

Copyright: Aboukameel et al. This is an open-access article distributed under the terms of the Creative Commons Attribution License 3.0 (CC BY 3.0), which permits unrestricted use, distribution, and reproduction in any medium, provided the original author and source are credited.

\section{ABSTRACT}

Emerging studies have shown that the expression of AR splice variants (ARv) lacking ligand-binding domain is associated with castrate-resistant prostate cancer (CRPC) and higher risk of tumor metastasis and recurrence. Nuclear export protein XPO1 regulates the nuclear localization of many proteins including tumor suppressor proteins. Increased XPO1 in prostate cancer is associated with a high Gleason score and bone metastasis. In this study, we found that high expression of AR splice variant 7 (AR-v7) was correlated with increased XPO1 expression. Silencing of XPO1 by RNAi or treatment with Selective Inhibitor of Nuclear Export (SINE) compounds selinexor and eltanexor (KPT-8602) down-regulated the expression of AR, AR-v7 and ARv567es at mRNA and protein levels. XPO1 silencing also inhibited the expression of AR and ARv regulators including FOXA1, Src, Vav3, MED1 and Sam68, leading to the suppression of ARv and AR target genes, UBE2C and PSA. By targeting XPO1/ ARv signaling, SINE suppressed prostate cancer ( $\mathrm{PCa}$ ) growth in vitro and in vivo and potentiated the anti-cancer activity of anti-AR agents, enzalutamide and abiraterone. Therefore, XPO1 inhibition could be a novel promising agent used in combination with conventional chemotherapeutics and AR-targeted therapy for the better treatment of PCa, especially CRPC.

\section{INTRODUCTION}

Prostate cancer $(\mathrm{PCa})$ remains the most common cancer and the second leading cause of cancer related deaths in men in the United States. The American cancer society estimated that 161,360 new cases of PCa will be diagnosed and 26,730 patients with PCa will die in 2017 [1]. The high mortality of patients with $\mathrm{PCa}$ is due to the development of castrate-resistant $\mathrm{PCa}$ (CRPC) that fails to respond to androgen deprivation therapy (ADT) and subsequently metastasizes. Growing evidence demonstrates that the molecular mechanisms involved in the development and progression of PCa and CRPC include alterations in androgen receptor (AR), Akt, Wnt, Hedgehog, and other signal transduction pathways [2-5]. One of the most important cellular signaling pathways 
involved in the development of PCa and CRPC is AR signaling [2]. AR is activated by androgen binding and translocates to nucleus to activate transcription of ARtarget genes. It is believed that AR over-expression and androgen hypersensitivity promote enhanced nuclear translocation and activation of AR signaling, which allows CRPC to proliferate in the presence of antiandrogen therapy. Emerging studies have shown that the expression of AR splice variants (ARv), which lack a ligand-binding domain, is increased in androgenindependent prostate cancer cell lines, CRPC, and metastatic PCa [6-10]. Although lacking a ligand binding domain, these ARv are constitutively activated and their transcriptional activity is not regulated by androgens or anti-androgens [11]. ARv are also associated with CRPC and a higher risk of tumor recurrence $[12,13]$. These findings suggest that prostate cancer cells expressing ARv could drive the development of the CRPC phenotype, tumor progression, recurrence and metastasis. Therefore, inhibiting ARv could be a promising strategy for the treatment of CRPC.

The nuclear export protein exportin-1 (XPO1, also known as CRM1) regulates the cellular localization of many proteins including tumor suppressor proteins (TSPs). XPO1 is overexpressed in various cancers including prostate cancer and is correlated with poor prognosis [14-16]. Moreover, increased XPO1 in prostate cancer has been found to be associated with increased Gleason score and bone metastasis [14]. It has been reported that selinexor, a Selective Inhibitor of Nuclear Export (SINE), covalently binds to the cargo binding pocket of XPO1, thus preventing the export of its many cargos. Inhibiting XPO1 mediated nuclear export with selinexor leads to an enrichment of cell cycle regulators and TSPs in the nucleus, which ultimately promotes cell cycle arrest and apoptosis [17]. Selinexor has also been found to reduce tumor spreading and improve overall survival in preclinical models of prostate cancer [18]. In vitro, treatment of prostate cancer cells with selinexor resulted in XPO1 inhibition, which led to the nuclear retention of p53 and Foxo proteins and the degradation of cyclin D1, survivin and XPO1, consequently triggering apoptosis [14, 19]. More significantly, in a Phase II study Selinexor demonstrated clinical activity in abiraterone- and/or enzalutamide-refractory mCRPC patients refractory to second-line anti-androgenic agents (NCT02215161) [20]. However, the detailed molecular mechanisms underlying SINE-inhibited prostate cancer growth are not clear. Whether SINE (selinexor and KPT-8602 which is a new generation SINE) could regulate important AR signaling in prostate cancer through modulation of $A R$ and $A R v$ remains unknown. Therefore, we investigated the in vitro and in vivo effects of SINE on the regulation of $\mathrm{AR}$ and $\mathrm{ARv}$ in prostate cancer and the molecular mechanisms underlying XPO1 regulated AR and ARv in order to design a novel therapeutic strategy for the treatment of prostate cancer and CRPC.

\section{RESULTS}

\section{PCa has high expression of XPO1 mRNA and the high expression of XPO1 is correlated with AR-v7 expression}

By utilizing and analyzing the mRNA microarray data in Oncomine database, we observed more than eight sets of data which showed higher expression of XPO1 mRNA in prostate cancer tissues compared to normal prostate gland tissue (Supplementary Figure 1). These results suggest that $\mathrm{PCa}$ cells express higher levels of XPO1, which could contribute to carcinogenesis and progression of $\mathrm{PCa}$. These results are consistent with the previous report showing that the high expression of XPO1 in PCa tissue is associated with an increased Gleason score and bone metastasis [14].

To determine the basal levels of AR and AR splice variants including AR-v7 and ARv567es, we conducted real-time RT-qPCR to measure the expression levels of these molecules in LNCaP, C4-2B, 22Rv1 and VCaP cells. We found that $22 \mathrm{Rv} 1$ and $\mathrm{VCaP}$ cells expressed significantly high level of AR splice variant AR-v7 compared to $\mathrm{LNCaP}$ and $\mathrm{C} 4-2 \mathrm{~B}$ cells and that $22 \mathrm{Rv} 1$ had highest expression of AR-v7 among these four cell lines (Figure 1A). In addition, $\mathrm{VCaP}$ cells showed much higher expression of ARv567es. Since both XPO1 and $\mathrm{ARv}$ are associated with progression of $\mathrm{PCa}$, we tested whether there is a connection between XPO1 and ARv. We found that $\mathrm{LNCaP}$ and $\mathrm{C} 4-2 \mathrm{~B}$ cells exhibit lower expression levels of AR splice variants, when compared to 22Rv1 and VCaP cells which harbor high levels of AR spice variants and XPO1 (Figure 1A). Furthermore, we tested the expression levels of AR-v7 and XPO1 in tumor tissues from the patients with $\mathrm{PCa}$. We found that the tumor tissues with high level of AR-v7 also expressed higher level of XPO1 (Figure 1B), suggesting that there could be a molecular interaction between XPO1 and AR splice variants.

\section{Silencing of XPO1 inhibits AR splice variants and their regulators}

Based on our observed connection between XPO1 and AR splice variants, we investigated whether XPO1 could regulate the expression of $\mathrm{AR}$ splice variants and their regulators. We transfected XPO1 siRNA into 22Rv1 PCa cells. We found that silencing XPO1 downregulated the expression of $A R$ splice variants (AR-v7 and ARv567es) and their regulators including FOXA1, MED1 and UBE2C (Figure 2A). FOXA1 and MED1 are co-regulators of AR splice variants $[21,22]$ and UBE2C is an AR splice variant target gene (Figure 2B) [23]. 
SINE significantly inhibits XPO1, AR and AR splice variants

Because silencing XPO1 using siRNA inhibited the expression of AR splice variants and their regulators, we tested the effects of SINE on expression of ARv and regulators. We treated $22 \mathrm{Rv} 1$ and $\mathrm{VCaP}$ cells with
$70-100 \mathrm{nM}$ selinexor or $200 \mathrm{nM}$ KPT-8602 for 48 hours and measured the mRNA expression levels of AR, AR-v7 and ARv567es before and after SINE treatment. We found that SINE significantly inhibited the mRNA expression of AR, AR-v7 and ARv567es (Figure 3A and 3B). To confirm if the protein levels of AR and ARv were also decreased after the downregulation of AR and ARv mRNAs by
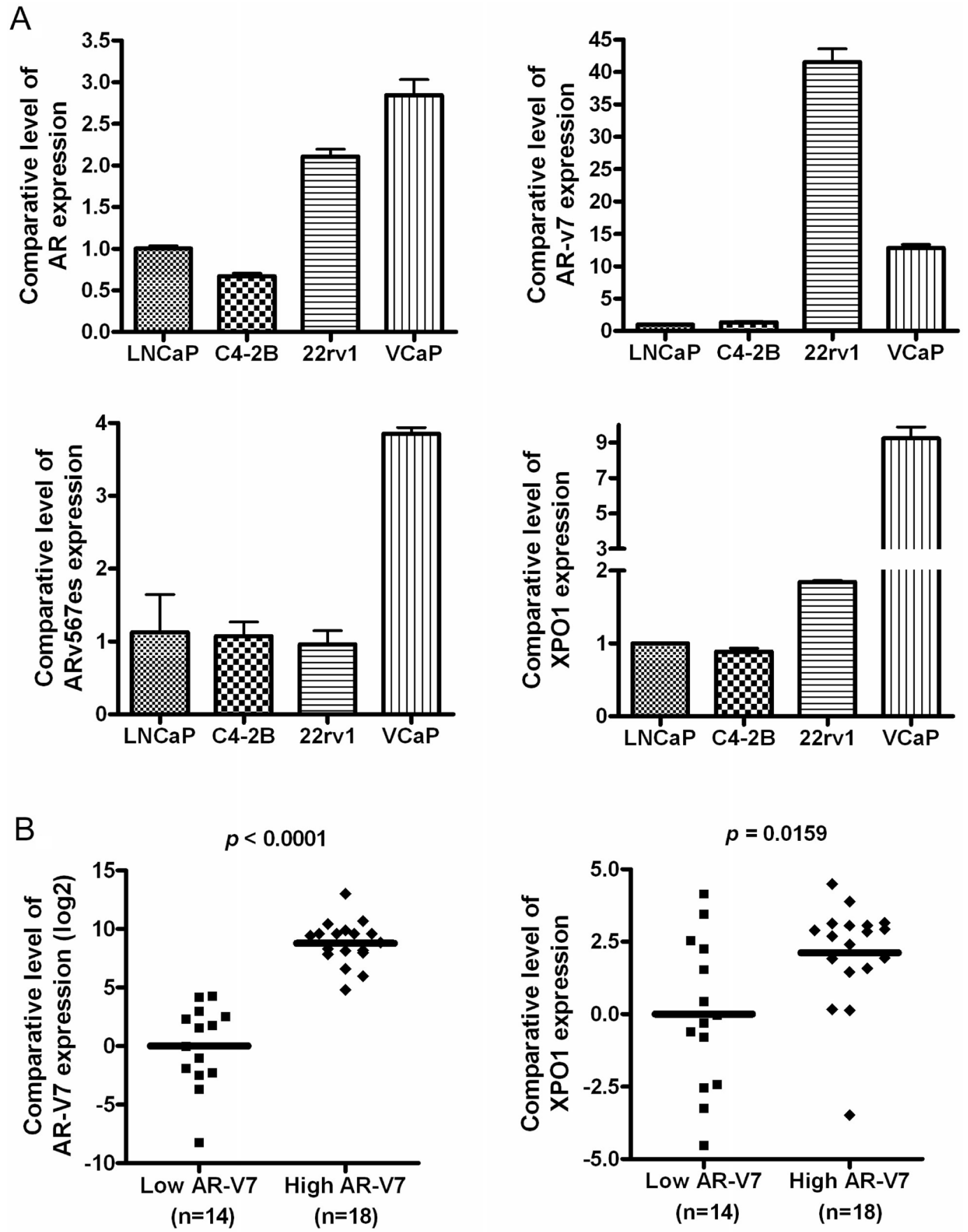

Figure 1: High expression of AR splice variants is correlated with over expression of XPO1 in PCa cells. (A) The expression levels of AR, AR-v7, ARv567es and XPO1 mRNA in 22Rv1, VCaP, LNCaP and C4-2B PCa cells were measured by using realtime RT-qPCR. (B) The expression levels of AR-v7 and XPO1 mRNA in paraffin-embedded tissues from 32 cases of PCa patients were assessed by real-time RT-qPCR. 
SINE, we conducted Western Blot analysis. Western blot analysis also showed that SINE significantly decreased protein levels of AR and ARv in 22Rv1 and VCaP cells after SINE treatment for 72 hours (Figure 3C). Since the transcriptional effects of AR and AR splice variants occur in nucleus, we isolated and separated cytosol and nuclear proteins, and tested the expression levels of AR and ARv before and after SINE treatment. We found that SINE downregulated the levels of AR and ARv in both cytoplasmic and nuclear compartments (Figure 3C).

To confirm that the down-regulation of AR and ARv is the direct effect of SINE rather than the effects of cell growth inhibition, we treated 22Rv1 and VCaP cells with $250 \mathrm{nM}$ selinexor for a short time (17 hours) when we did not observe cell growth inhibition. We found that selinexor treatment at short time also significantly inhibited the expression of AR and ARv at mRNA and protein levels (Supplementary Figure 2A and 2B). Moreover, selinexor significantly decreased the levels of AR and ARv in both cytoplasmic and nuclear compartments (Supplementary Figure 2B). These results suggest the direct inhibitory effects of selinexor on AR and AR splice variants.

\section{SINE inhibits the molecules which regulate ARv and its targets}

We conducted molecular experiments to further investigate the molecular mechanisms of SINE action on
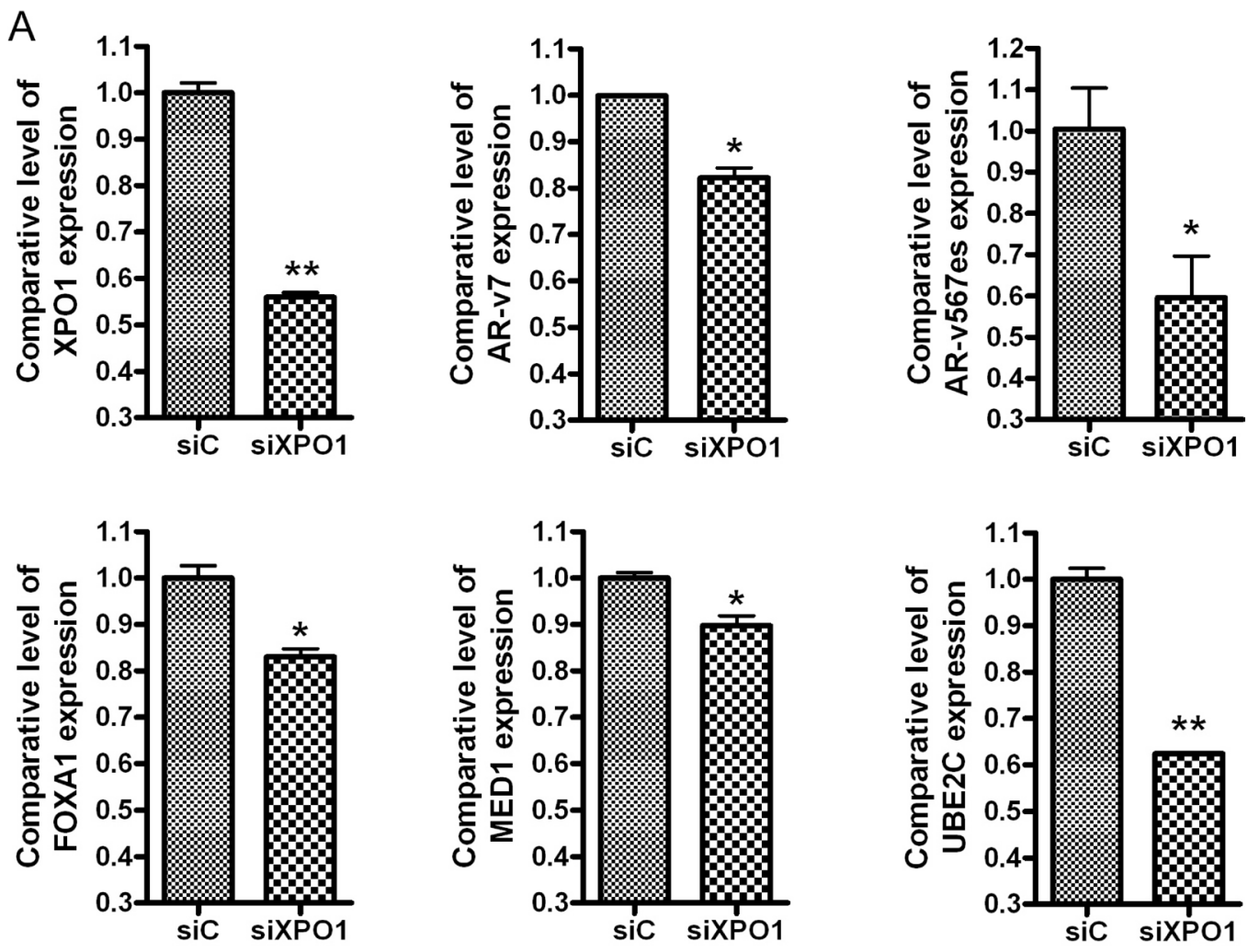

$\mathrm{B}$

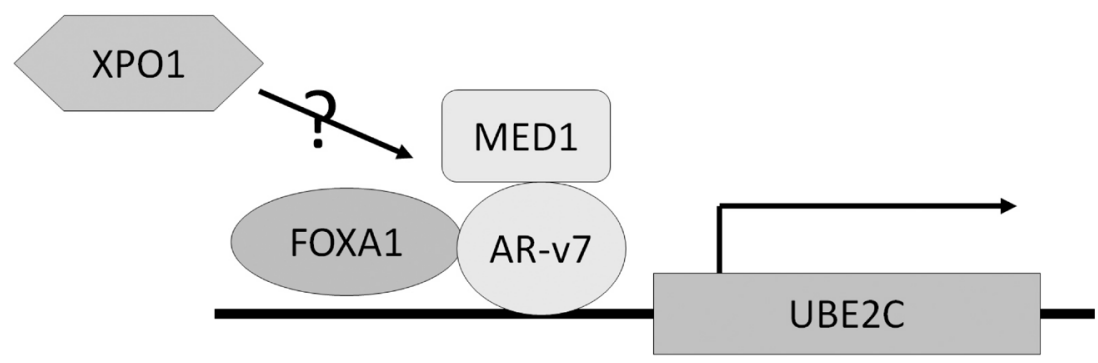

Figure 2: Silencing of XPO1 inhibits AR splice variants and their regulators. (A) $22 \mathrm{Rv} 1$ cells were transfected with XPO1 siRNA. The expressions of XPO1, AR-v7, ARv567es, FOXA1, MED1 and UBE2C mRNA were tested by using real-time RT-qPCR. (B) The diagram showing possible regulatory mechanism underlying XPO1 regulated AR splice variant signaling. 

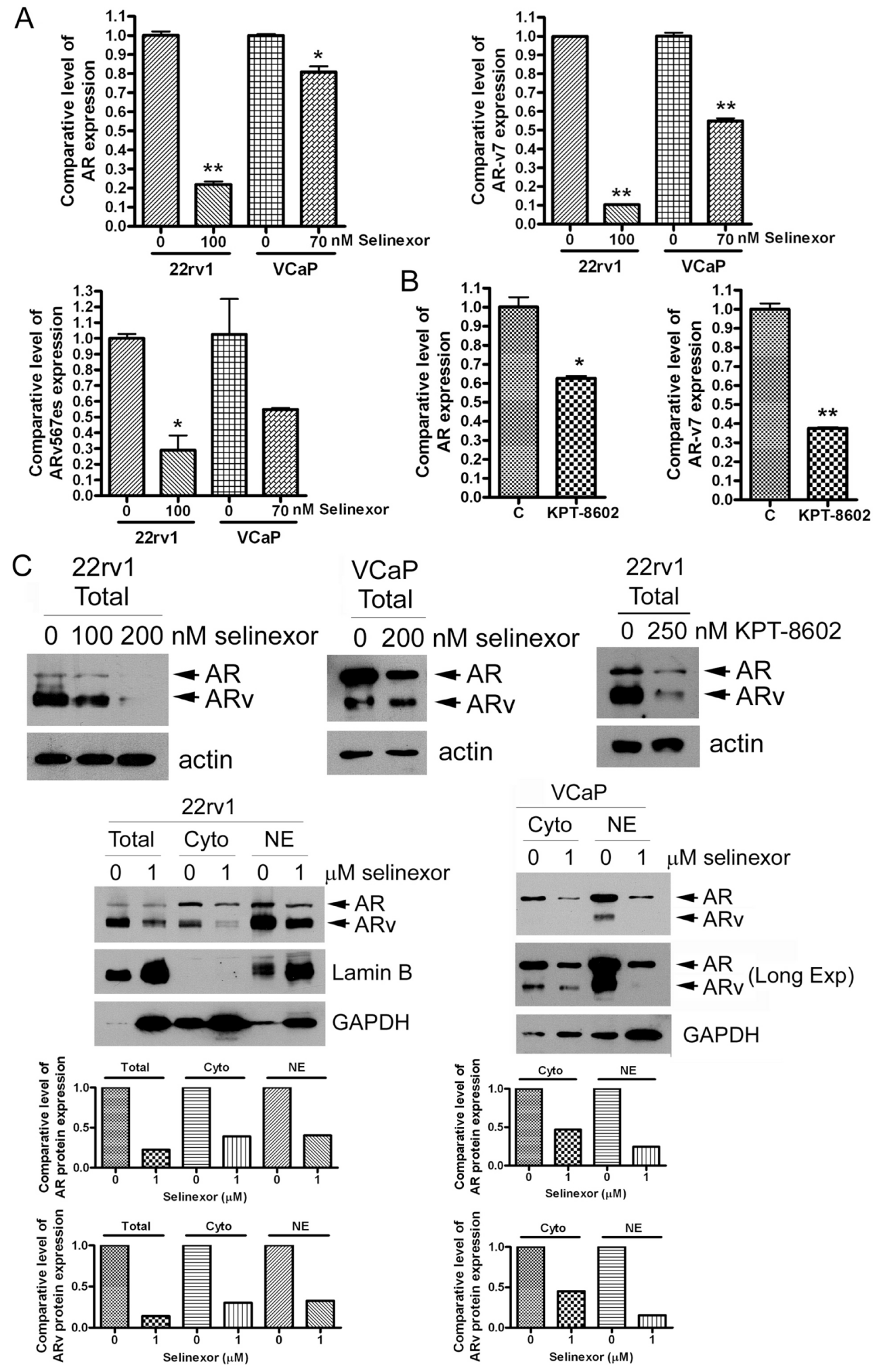

Figure 3: SINE significantly inhibits AR and AR splice variants. 22Rv1 and VCaP cells were treated with 70-100 nM selinexor (A) or $200 \mathrm{nM} \mathrm{KPT-8602} \mathrm{for} 48$ hours (B). The expressions of AR, AR-v7 and ARv567es mRNA were accessed by real-time RT-qPCR $\left({ }^{*} p<0.05 ;{ }^{* *} p<0.01\right)$. (C) $22 \mathrm{Rv} 1$ and VCaP cells were treated with 100-200 nM selinexor or $250 \mathrm{nM} \mathrm{KPT}-8602$ for 72 hours and total proteins were extracted from these cells. 22Rv1 and $\mathrm{VCaP}$ cells were also treated with $1 \mu \mathrm{M}$ selinexor for 24 hours and cytoplasmic and nuclear proteins were separately extracted from these cells. The expression levels of AR and ARv proteins were measured by using Western Blot analysis. The signal was quantified by using AlphaEaseFC and the expression level of AR and ARv was calculated and normalized by Lamin B for nuclear protein and GAPDH for total and cytoplasmic proteins. 
the regulation of $A R$ and $A R v$. We found that in $22 \mathrm{Rv} 1 \mathrm{PCa}$ cells, SINE down-regulated mRNA and protein expression levels of FOXA1, Src, MED1, and Vav3 (Figure 4A-4C) which are known regulators of AR or ARv [21, 22, 24-26], suggesting that the inhibition of AR and ARv signaling by SINE could be mediated through these regulators. We also conducted immunoprecipitation assay to investigate the effects of selinexor on the interaction of FOXA1 and AR/ARv. We found that selinexor significantly inhibited AR/ARv binding to FOXA1 (Figure 4D), leading to the downregulation of transcription of UBE2C (Figure 4A and $4 \mathrm{~B}$ ), which is a downstream effector of AR splice variants (Figure 4E). Selinexor also down-regulated the expression of PSA (Figure 4A) which is a downstream target of AR (Figure 4E). These results suggest that the downregulation of ARv and AR signaling by SINE could be mediated through the inhibition of FOXA1/ARv or AR signal transduction.

To confirm the effect of SINE on FOXA1 and UBE2C is mediated through the regulation of XPO1, we treated HEK293 XPO1 wild-type and mutant (C528S) cells with SINE. XPO1 Cys528 is SINE binding site. The down-regulation of FOXA1 and UBE2C by SINE was observed in XPO1 wild-type cells and was not seen in XPO1 mutant (C528S) cells (Figure 4F), suggesting that the down-regulation of FOXA1 and UBE2C by SINE is mediated through XPO1 signaling.

\section{SINE regulates eukaryotic initiation factor 4E (eIF4E) to retain ARv RNA in nuclear compartment}

To investigate the mechanism underlying the downregulation of $A R$ and $A R-v 7$ by SINE, we measure the level of eIF4E in cytoplasmic and nuclear compartments before and after SINE treatment. eIF4E is responsible for the nuclear export and translation initiation of cappeddependent mRNAs $[27,28]$. We found that SINE treatment retained eIF4E protein in nuclear compartment (Figure 5A and $5 \mathrm{~B}$ ), leading to nuclear retention of AR-v7 (Figure 5C) and PSA mRNA (Figure 5D). The nuclear retention of AR$\mathrm{v} 7 \mathrm{mRNA}$ resulted in the reduction in the protein levels of ARv (Figure 3C). In addition, the deceased levels of AR and AR-v7 mRNA (Figure 3A and 3B) also contributed to the reduction of $A R$ and $A R v$ proteins observed in Figure 3C.

\section{SINE potentiates the anti-cancer activity of enzalutamide and abiraterone}

Since we observed the inhibitory effect of SINE on AR/ARv signaling, we tested the anti-cancer activity of SINE. We treated 22Rv1 and VCaP PCa cells with different concentration of selinexor (from $12.5 \mathrm{nM}$ to $400 \mathrm{nM})$. We found that selinexor significantly inhibited the proliferation of 22Rv1 and VCaP cells (Figure 6A), suggesting that the anti-cancer activity of SINE could be mediated through the down-regulation of AR/ ARv signaling. Furthermore, we investigated whether selinexor could potentiate the anti-cancer activity of new anti-AR agents (enzalutamide and abiraterone) through the downregulation of AR and ARv. We treated 22Rv1 prostate cancer cells with selinexor (50-200 nM), enzalutamide $(5-20 \mu \mathrm{M})$, abiraterone $(5-20 \mu \mathrm{M})$, or combination of selinexor with enzalutamide or abiraterone. Isobologram analysis showed that selinexor combined with enzalutamide or abiraterone synergistically inhibited the cell proliferation (Figure 6B). Combination index $(\mathrm{CI})$ at experimental conditions was less than 1 (Figure 6B), suggesting the synergistic effects of selinexor with enzalutamide or abiraterone on cell proliferation. Moreover, the combination treatment with selinexor and enzalutamide significantly inhibited the expression of AR, AR-v7, FOXA1, PSA and UBE2C (Figure 6C). These results demonstrate that SINE potentiates the anti-cancer proliferation activity of enzalutamide and abiraterone through the down-regulation of AR/ARv signaling.

\section{SINE inhibits tumor growth, potentiates anti- tumor activity of abiraterone and prolongs survival of a $22 \mathrm{Rv} 1$ xenograft}

To investigate the effects of SINE on tumor growth in vivo, we conducted animal experiments. We evaluated the efficacy of selinexor (10 mg/kg, QoDx3/week) and KPT-8602 (15 mg/kg, QDx5/week) in a 22Rv1 xenograft model in male CB.17 SCID mice. We found that \%TGI on Day 16 was $84 \%$ and $87 \%$ by selinexor and KPT- 8602 , respectively, when compared to the vehicle (Figure 7A). Moreover, Kaplan-Meier plot analysis showed that vehicle treated mice had a median OS of 20 days while both SINE treatment groups had an undefined median OS at end of the study (Day 37) (Figure 7B). These results suggest that SINE significantly inhibits tumor growth and prologs survival of 22Rv1 xenograft.

Moreover, we evaluated the efficacy of combination treatment with KPT-8602 and abiraterone in the 22Rv1 xenograft model. We found that the combination treatment with KPT-8602 and abiraterone significantly inhibited the growth of 22Rv1 tumors in mice (Figure 7C and 7D) with significant suppression of AR (Figure 7E) and ARv (Figure $7 \mathrm{~F}$ ). These in vivo results are consistent with the in vitro data (Figure 6B) showing that SINE and abiraterone synergistically inhibited prostate cancer growth.

\section{SINE retains TSP in nucleus to inhibit cell proliferation and induce apoptosis}

We further conducted immunohistochemistry analysis to demonstrate the retention of TSPs in nucleus of cancer cells in vivo after SINE treatment. The immunohistochemistry analysis of xenograft samples 

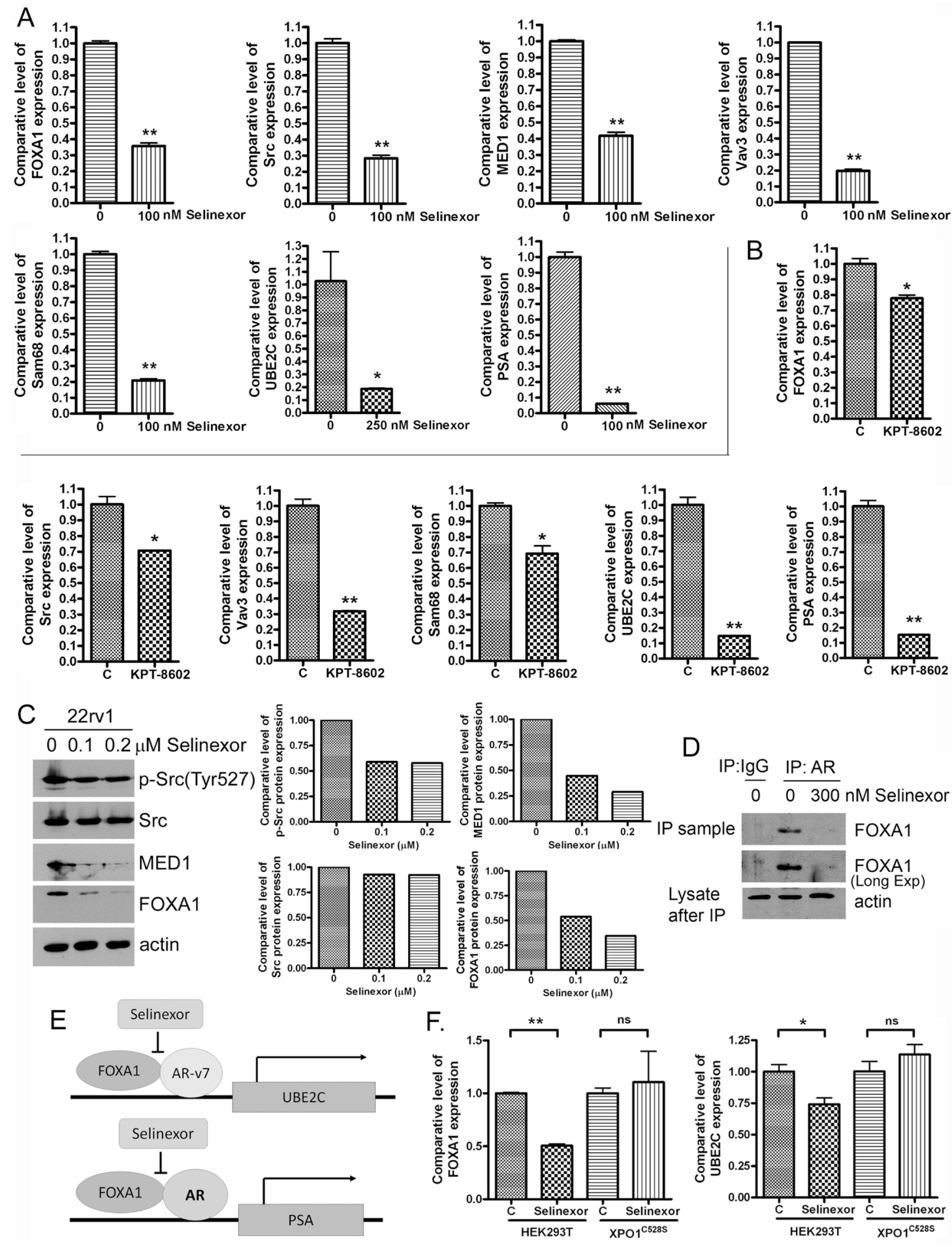

Figure 4: SINE inhibits regulators and targets of ARv and AR. 22Rv1 cells were treated with $100 \mathrm{nM}$ selinexor (A) or $200 \mathrm{nM}$ KPT-8602 for 48 hours (B). The expressions of FOXA1, Src, MED1, Vav3, Sam68, UBE2C and PSA mRNAs were accessed by real-time RT-qPCR $\left({ }^{*} p<0.05 ;{ }^{* *} p<0.01\right)$. (C) $22 \mathrm{Rv} 1$ were treated with $100-200 \mathrm{nM}$ selinexor for 72 hours and total proteins were extracted from these cells. The expression levels of p-Src, Src, MED1 and FOXA1 proteins were measured by using Western Blot analysis. The signal was quantified by using AlphaEaseFC and the expression level was calculated and normalized by actin. (D) The cell lysate from control and $300 \mathrm{nM}$ selinexor treated 22Rv1 cells were immunoprecipitated with IgG or AR antibody which recognizes AR and ARv. Western Blot analysis was then conducted for testing FOXA1 binding to AR and ARv. (E) The diagram showing the regulatory mechanisms by which selinexor inhibits ARv, AR and their down-stream targets. (F) HEK293 XPO1 wild-type and mutant (C528S) cells were treated with $500 \mathrm{nM}$ selinexor for 48 hours. The expressions of FOXA1 and UBE2C mRNAs were accessed by real-time RT-qPCR ( ${ }^{*} p<0.05$; ns: $p>0.05$ ). 
derived from 22Rv1 cells treated with vehicle control, selinexor or KPT-8602 showed decreased cell proliferation marker (Ki67) and increased apoptotic molecule (Cleaved Caspase 3) in samples treated with SINE compounds (Supplementary Figure 3). The increased cleaved Caspase 3 was consistent with increased apoptosis observed by Annexin V FITC assay (Figure 7G). Increased nuclear staining of TSPs Rb, p21, p53, APC and SMAD4 were also observed in samples treated with SINE compounds (Supplementary Figure 3).

\section{DISCUSSION}

High expression of XPO1 has been found in many types of solid and hematopoietic malignant tumors including cervical cancer, prostate cancer, ovarian cancer, pancreatic cancer, gastric cancer, osteosarcoma, glioma, multiple myeloma, lymphoma and leukemia [14, 29-37].
The increased expression of XPO1 positively correlates with disease progression and reduced survival in these malignances. Although only one study has reported increased expression of XPO1 in prostate cancer tissue [14], the data from Oncomine database shows that more than 8 sets of mRNA expression profiles including XPO1 from PCa tissues (total 342 cases) and normal prostate gland tissues (total 170 cases) were tested by miRNA microarray. The Oncomine analysis tool reveals a higher expression of XPO1 in PCa tissues when compared to normal prostate gland tissues. The high expression of XPO1 in PCa tissues has been reported to be associated with a high Gleason score and bone metastasis [14]. These findings suggest the important role of XPO1 in the development and progression of PCa. More importantly, we found that the expression of XPO1 is correlated with high expression of AR-v7 which has been known as an important marker for disease progression and drug

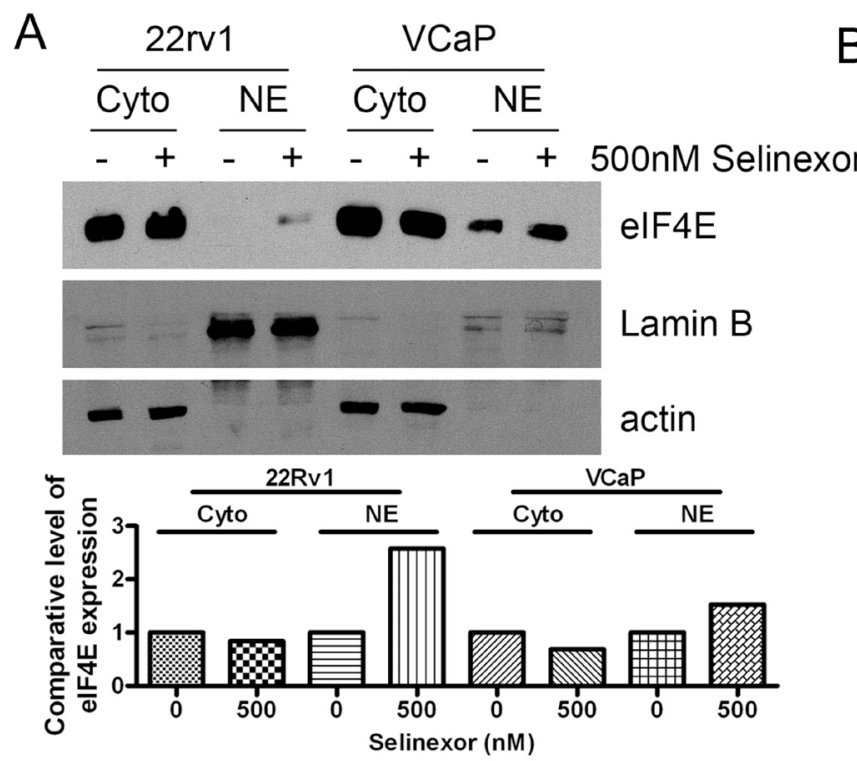

B
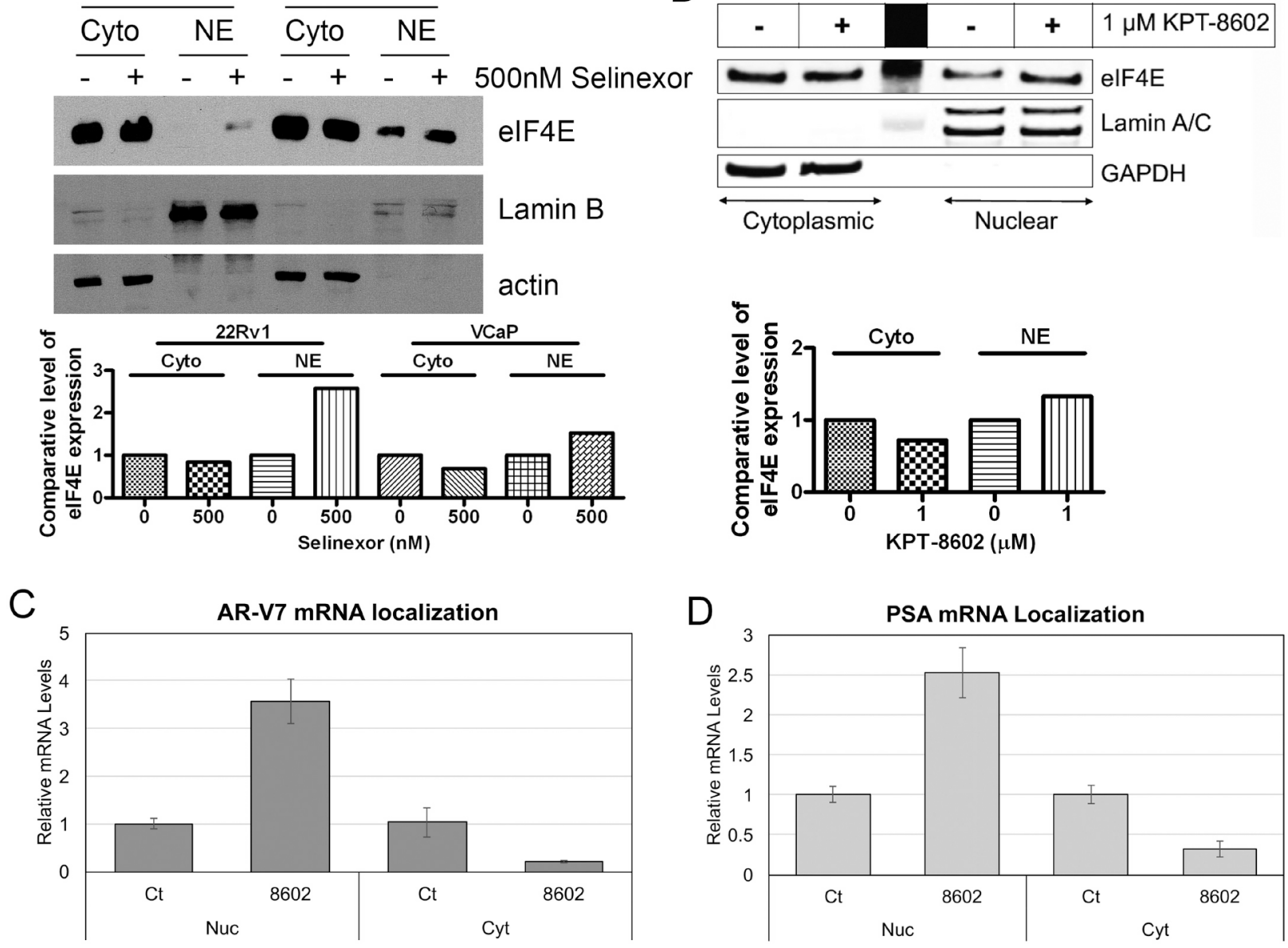

Figure 5: SINE regulates eIF4E to retain AR-v7 RNA in nuclear compartment. 22Rv1 and VCaP cells were treated with $500 \mathrm{nM}$ selinexor (A) or $1 \mu \mathrm{M}$ KPT-8602 (B) for $24 \mathrm{hrs}$. Cytoplasmic and nuclear proteins were extracted and the expression of eIF4E was assessed by Western Blot analysis. The signal was quantified by using AlphaEaseFC and the expression level of eIF4E was calculated and normalized by Lamin for nuclear protein and actin or GAPDH for cytoplasmic protein. (C and D) RNA was isolated as nuclear (Nuc) and cytoplasmic (Cyt) fractions using the RNA Subcellular Isolation Kit. Real-time RT-qPCR was conducted for measurement of AR-v7 (C) and PSA (D) mRNAs. 
resistance in CRPC and PCa bone metastasis [6, 7, 9, 11]. We also found that silencing XPO1 down-regulates the expression of AR splice variants and their regulators. These results suggest that there is a relationship between XPO1 and AR splice variants. High expression of both XPO1 and AR-V7 could lead to constitutively activated
AR signaling, CRPC development and progression, and anti-AR drug resistance.

Currently, the mechanisms underlying the XPO1 mediated regulation of $\mathrm{AR}$ and $\mathrm{AR}$ splice variants remains unknown. It has been reported that compounds targeting Src family kinases down-regulated expression
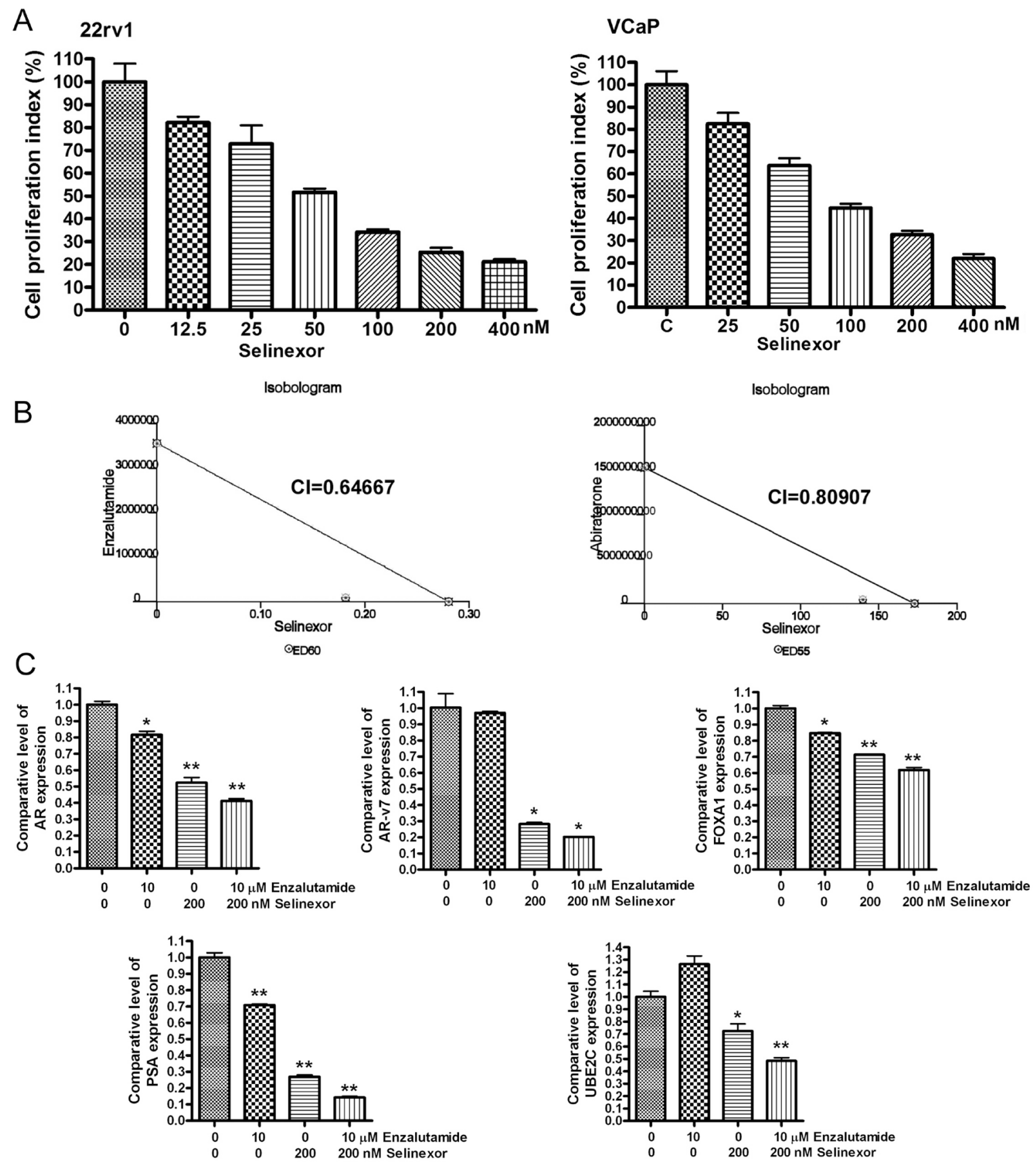

Figure 6: SINE potentiates the anti-cancer proliferation activity of enzalutamide and abiraterone. (A) $22 \mathrm{Rv} 1$ and $\mathrm{VCaP}$ cells were treated with $12.5-400 \mathrm{nM}$ selinexor for 72 hours. MTT assay was conducted to assess cell proliferation index. (B) $22 \mathrm{Rv} 1 \mathrm{cells}$ were treated with 50-200 nM selinexor, 5-20 $\mu \mathrm{M}$ enzalutamide, 5-20 $\mu \mathrm{M}$ abiraterone, or combination of selinexor with enzalutamide or abiraterone for 72 hours. MTT assay and isobologram analysis were conducted to assess the combination index (CI). (C) 22Rv1 cells were treated with $200 \mathrm{nM}$ selinexor, $10 \mu \mathrm{M}$ enzalutamide, or combination for 48 hours. The expression levels of AR, AR-v7, FOXA1, PSA and UBE2C mRNA were assessed by real-time RT-qPCR $\left({ }^{*} p<0.05 ;{ }^{* *} p<0.01\right)$. 

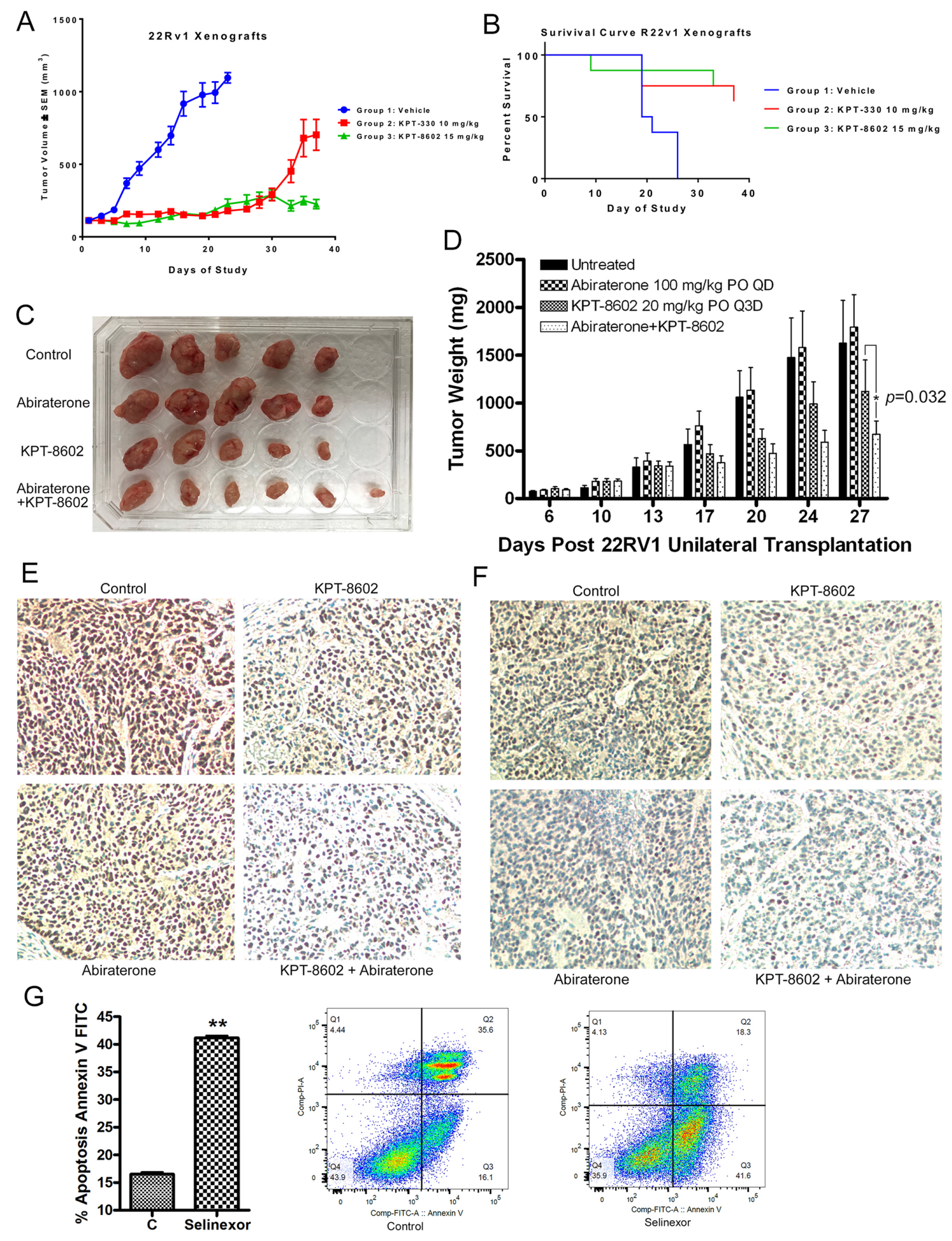

Figure 7: SINE inhibits tumor growth and prolongs survival of a $22 \mathrm{Rv} 1$ xenograft through retention of TSPs. (A) \% TGI on Day 16 was $84 \%$ and $87 \%$ by selinexor and KPT-8602, respectively, when compared to the vehicle. (B) Kaplan-Meier plot shows that vehicle treated mice have a median OS of 20 days while both SINE treatment groups have an undefined median OS at end of the study (Day 37). (C and D) KPT-8602 and abiraterone combination treatment significantly inhibited the growth of tumors in mice, showing decreased tumor size (C) and weight (D). The mouse tumor tissues with KPT-8602 and/or abiraterone were immunochemistry stained with anti-AR (E) or anti-ARv (F) antibodies. (G) $22 \mathrm{Rv} 1$ cells were treated with $250 \mathrm{nM}$ selinexor for 48 hour. The apoptotic cell death was tested by Annexin V FITC assay. 
and nuclear translocation of AR-v7 and inhibited ligandindependent transcription of AR target genes, suggesting that Src is an important upstream regulator of AR-v7 [26]. The RNA-binding protein Sam68 is another molecule which regulates the expression and activity of AR splice variants. Sam 68 controls transcription of AR exon $3 \mathrm{~b}$, causing up-regulation of endogenous AR-v7 mRNA and AR-v7 protein [25]. Moreover, Sam68 activates ligandindependent transcriptional activity AR-v7 and induces the expression of AR-v7 target gene UBE2C [25], suggesting that Sam68 is an AR-v7 regulator. Vav3 is an AR coactivator; however, it also activates AR splice variants. It has been reported that Vav3 significantly promoted the transcriptional activity of AR splice variants including AR-v7 and ARv567es [24]. Knockdown of Vav3 or AR-v7 significantly inhibits ligand-independent AR activity, leading to suppression of $\mathrm{PCa}$ cell proliferation [24]. These findings demonstrate the regulatory effects of Vav3 on AR splice variants. Moreover, a recent study also demonstrates that FOXA1 regulates activity of AR splice variants in models of CRPC. It has been found that reduction of FOXA1 in AR-v7 containing 22Rv1 cells abrogated the oncogenic potential of AR splice variants [22]. Gene expression profiling showed that approximately $41 \%$ of AR splice variant transcriptome requires FOXA1, suggesting the regulatory effect of FOXA1 on AR splice variants [22]. Similar to FOXA1, MED1 also mediates ARv induced gene expression in the absence of ligand [21]. MED1 binds to ARv567es and promotes ARv567es induced UBE2C expression [21]. These results indicate that MED1 is a key regulator of $\mathrm{ARv}$ in the development and progression of CRPC. UBE2C is an important cell cycle gene enriched in CRPC. A study found that suppression of ligand-mediated AR signaling by enzalutamide or abiraterone caused increased expression of AR-v7 and ARv567es which are constitutively activated, leading to the increased expression of UBE2C and drug resistance [23]. In present study, we found that SINE down-regulated the above mentioned ARv regulations including Src, Sam68, Vav3, FOXA1 and MED1, leading to the decreased expression of ARv target gene UBE2C (Figure 4E). SINE also inhibited the expression of $\mathrm{AR}$, resulting in the downregulation of AR target genes such as PSA. The downregulation of $\mathrm{ARv}$ target gene $\mathrm{UBE} 2 \mathrm{C}$ and $\mathrm{AR}$ target genes by SINE suppresses PCa cell growth, which could be one of the molecular mechanisms by which SINE inhibits PCa growth and viability.

XPO1 is responsible for the exporting many TSPs from the nucleus to the cytoplasm, leading to a dysregulation of TSP localization and activity [38, 39]. In this study, we found that XPO1 inhibition by SINE compounds promotes the retention of TSPs including $\mathrm{Rb}, \mathrm{p} 21, \mathrm{p} 53, \mathrm{APC}$ and SMAD4 in nucleus of PCa cells,. Interestingly, we also found that SINE retained eIF4E protein in nucleus. eIF4E plays a critical role in
mRNA translation by binding the 5'-cap structure of the mRNA [40]. It controls the nuclear export and translation initiation of capped-dependent mRNAs [27, 28, 41]. Retention of eIF4E protein in nucleus by SINE results in the retention of AR-v7 and PSA mRNA in nucleus, leading to the reduced levels of AR-v7 and PSA protein, which could be one of the mechanisms underlying the downregulation of AR, ARv and PSA by SINE. However, more mechanistic studies are needed to full understand how SINE regulates ARv mRNA.

In recent years, enzalutamide and abiraterone have been used as anti-AR drugs in AR-targeted therapies. Abiraterone is an inhibitor of CYP17 which is critical for androgen synthesis. By targeting CYP17, abiraterone decreases the level of circulating and intratumoral androgens, leading to the down-regulation of AR signaling [42]. Due to its steroidal structure, abiraterone also inhibits other molecules in AR pathway [42]. Enzalutamide is an inhibitor of AR signaling. By binding to the ligandbinding domain of AR, enzalutamide suppresses AR nuclear translocation and binding to DNA, leading to down-regulation of AR target genes [43, 44]. Treating $\mathrm{PCa}$ patients with abiraterone and enzalutamide improves response rates and overall survival. However, patients using abiraterone and enzalutamide commonly develop resistance to these agents [45, 46]. One of the key mechanisms involved in resistance to abiraterone and enzalutamide is the expression of constitutively activated AR splice variants that are refractory to anti-AR therapies $[23,45]$. The anti-AR treatment-induced AR splice variants activate cell cycle genes such as UBE2C without requiring the presence of full length AR, leading to PCa survival and progression in castrate conditions [23]. In this study, we found that SINE significantly inhibited the expressions of XPO1, AR and AR splice variants, which make SINE a promising therapeutic for the treatment of $\mathrm{PCa}$.

Because SINE inhibits ARv, SINE could sensitize PCa cells to anti-AR therapy. Indeed, we found that SINE in vitro and in vivo potentiated the anti-cancer activity of anti-AR agents, enzalutamide and abiraterone, by inhibition of XPO1 and AR splice variants. Our in vitro and in vivo findings are supported by clinical observations as well [20]. In this Phase II study (NCT02215161), fourteen patients were $60 \mathrm{mg}$ flat dose twice a week (days 1 and 3), 3 weeks on, 1 week off with a median treatment duration of 13 weeks. At a median follow-up of 4 months, two patients $(14 \%)$ had $\geq 50 \%$ prostatespecific antigen (PSA) decline, and seven patients (50\%) had any PSA decline. Of eight patients with measurable disease at baseline, two $(25 \%)$ had a partial response and four $(50 \%)$ had stable disease as their best radiographic response. Despite these positive results, several patients experienced serious adverse events (SAEs). Nevertheless, these SAEs were unrelated to selinexor), and five patients (36\%) experienced treatment-related grade3-4 AEs. The most common drug-related adverse events (AEs) of any 
severity were anorexia, nausea, weight loss, fatigue, and thrombocytopenia. The new generation SINE KPT8602 has better tolerability. Therefore, we anticipate the outcome of our studies would lead to the introduction of KPT8602 in combination with conventional chemotherapeutics and AR-targeted therapy for the better treatment of PCa, especially CRPC.

\section{MATERIALS AND METHODS}

\section{Cell lines, reagents and antibodies}

22Rv1, VCaP, and LNCaP cells were purchased from American Type Culture Collection (ATCC, Manassas, VA) and maintained in RPMI1640 (Invitrogen, Carlsbad, CA) supplemented with 10\% fetal bovine serum (FBS), $100 \mathrm{U} /$ $\mathrm{mL}$ penicillin and $100 \mu \mathrm{g} / \mathrm{mL}$ streptomycin in a $5 \% \mathrm{CO}_{2}$ atmosphere at $37^{\circ} \mathrm{C}$. HEK293 XPO1 wild-type and mutant (C528S) were developed as described previously [47]. The cell lines have been tested and authenticated in a core facility of the Applied Genomics Technology Center at Wayne State University. The method used for testing was short tandem repeat (STR) profiling using the PowerPlex ${ }^{\circledR}$ 16 System from Promega (Madison, WI). SINE including selinexor and KPT-8602 (Karyopharm Therapeutics, Newton, MA) were dissolved in DMSO to make a $1 \mathrm{mM}$ stock solution. Anti-AR (N20) which recognizes both AR full length and AR splice variants (Santa Cruz, Santa Cruz, CA), anti-XPO1 (Santa Cruz), anti-FOXA1 (Novus Biologicals, Littleton, CO), anti-MED1 (Santa Cruz), anti-eIF4E (Cell Signaling, Danvers, MA), antiSrc (Cell Signaling), anti-p-Src(Tyr527) (Cell Signaling), anti-Lamin B (Invitrogen), and anti- $\beta$-actin (Sigma, St. Louis, MO) primary antibodies were used for Western Blot analysis.

\section{RNA isolation and mRNA real-time RT-qPCR}

Total RNAs from PCa cell lines treated with SINE were extracted and purified by using the RNeasy Mini Kit and RNase-free DNase Set (QIAGEN, Valencia, CA) following the protocol provided by the manufacturer. Total RNAs from PCa tissues were isolated from formalin-fixed, paraffin-embedded tissue sections by using miRNeasy FFPE Kit (QIAGEN) following the protocol provided by the company. Retrospective archival PCa tissues were collected from patients who underwent routine radical prostatectomy at Karmanos Cancer Institute and obtained from Biospecimen Core of Karmanos Cancer Institute after obtaining institutional review board approval. The expression levels of AR, AR-v7, ARv567es, PSA, XPO1, FOXA1, MED1, Src, Vav3, Sam68, or UBE2C in selinexor or KPT-8602 treated or un-treated PCa cells and PCa tissues were analyzed by real-time RT-qPCR using High Capacity cDNA Reverse Transcription Kit and
SYBR Green Master Mixture from Applied Biosystems (Waltham, MA). The sequences of primers used are listed in Table 1 . The qPCR was initiated by $10 \mathrm{~min}$ at $95^{\circ} \mathrm{C}$ before 40 thermal cycles, each of $15 \mathrm{~s}$ at $95^{\circ} \mathrm{C}$ and $1 \mathrm{~min}$ at $60^{\circ} \mathrm{C}$ in a StepOnePlus real-time PCR system (Applied Biosystems). Data were analyzed according to the comparative $\mathrm{Ct}$ method and were normalized by actin and/or 18S rRNA expression in each sample.

\section{Separation of cytoplasmic and nuclear RNA}

RNA from selinexor or KPT-8602 treated 22Rv1 cells was isolated as cytoplasmic and nuclear fractions using the RNA Subcellular Isolation Kit. The ARv7 and PSA mRNA levels in cytoplasmic and nuclear compartments were measured by real-time RT-qPCR using the following taqman assays (Hs00171172_ml AR, Hs00907242_m1 AR, and Hs02576345_m1 KLK3).

\section{Preparation of total, cytoplasmic and nuclear protein lysates}

For total protein extraction, PCa cells treated or untreated with SINE were lysed in RIPA buffer and protein concentration was measured using BCA protein assay (PIERCE, Rockford, IL). For cytoplasmic and nuclear protein extraction, $\mathrm{PCa}$ cells with and without SINE treatment were harvested and incubated in ice-cold cell lysis buffer (10 mM HEPES pH7.9, $10 \mathrm{mM} \mathrm{KCl,} 0.1 \mathrm{mM}$ EDTA, 0.1 mM EGTA, 1 mM DTT, 0.5 mM PMSF, 1X protease inhibitor cocktail) on ice. After 15 minutes, NP40 was added to the cell suspension at a final concentration of $0.3 \%$ and the samples were vortexed vigorously for 20 seconds. After centrifugation, the supernatant was saved as cytoplasmic protein and the nuclear pellet was incubated in ice-cold nuclear extraction buffer (20 mM HEPES pH7.9, 0.4 M NaCl, 1 mM EDTA, 1 mM EGTA, 1 mM DTT, $0.5 \mathrm{mM}$ PMSF, 1X protease inhibitor cocktail) on ice for 30 minutes. After centrifugation, the supernatant was saved as nuclear protein and protein concentration was measured using BCA Protein Assay (PIERCE).

\section{Immunoprecipitation}

Total lysate $(300 \mu \mathrm{g})$ from each sample were diluted and subjected to immunoprecipitation using $5 \mu \mathrm{g}$ of anti-AR (N20) antibody or normal rabbit IgG (Cell Signaling). The lysate and antibody mixtures were incubated overnight at $4^{\circ} \mathrm{C}$ with rotation. After adding $30 \mu \mathrm{l}$ of Protein G Agarose (Santa Cruz) and incubation for 2 hour, the samples were centrifuged. The agarose pellet was then washed three times, resuspended in $50 \mu \mathrm{l}$ of Laemmli buffer with 2-mercaptoethanol, and boiled for 5 minutes. Boiled samples were centrifuged and supernatant was used for Western Blot analysis. 


\begin{tabular}{|c|c|c|}
\hline Primers & & quences \\
\hline \multirow{2}{*}{ AR } & Forward & GACTTCACCGCACCTGATG \\
\hline & Reverse & AATGGGCAAAACATGGTCCC \\
\hline \multirow{2}{*}{ AR-v7 } & Forward & TGTCCATCTTGTCGTCTTCGG \\
\hline & Reverse & TGCAATTGCCAACCCGGAAT \\
\hline \multirow{2}{*}{ ARv567es } & Forward & TTGTACACGTGGTCAAGTGGG \\
\hline & Reverse & TGAACTGATGCAGCTCTCTCG \\
\hline \multirow{2}{*}{ PSA } & Forward & GTCCCGGTTGTCTTCCTCAC \\
\hline & Reverse & CTCCCACAATCCGAGACAGG \\
\hline \multirow{2}{*}{ XPO1 } & Forward & ACGAGGAAGGAAGGAGCAGT \\
\hline & Reverse & CGAGCTGCATGGTCTGCTAA \\
\hline \multirow{2}{*}{ FOXA1 } & Forward & ACCAGCGACTGGAACAGCTA \\
\hline & Reverse & GTCATGTTGCCGCTCGTAGT \\
\hline \multirow{2}{*}{ MED1 } & Forward & GCTTGTGCGTCAAGTCATGG \\
\hline & Reverse & TGAGATGAGAGCCCAGTCCA \\
\hline \multirow{2}{*}{ Src } & Forward & TGTTCGGAGGCTTCAACTCC \\
\hline & Reverse & TGTGTTGTTGACAATCTGGAGC \\
\hline \multirow{2}{*}{ Vav3 } & Forward & GGACTCGGCTCAGGTGTTCG \\
\hline & Reverse & GCCCGGAGGTTGTTAAGCAG \\
\hline \multirow{2}{*}{ Sam68 } & Forward & TGAGAGACAAAGCCAAGGAGG \\
\hline & Reverse & CTCACATGGGGGTCCAAAGA \\
\hline \multirow{2}{*}{ UBE2C } & Forward & TCCTGTCTCTCTGCCAACGC \\
\hline & Reverse & TTGTCTGATTCAGGGAAGGCA \\
\hline \multirow{2}{*}{ actin } & Forward & GCACAGAGCCTCGCCTT \\
\hline & Reverse & TCATCATCCATGGTGAGCTG \\
\hline \multirow{2}{*}{$18 \mathrm{~S}$} & Forward & GCAATTATTCCCCATGAACG \\
\hline & Reverse & GGCCTCACTAAACCATCCAA \\
\hline
\end{tabular}

\section{Western blot analysis}

Western Blot analysis was conducted to measure the alterations in the protein expression of genes. Briefly, the total, cytoplasmic, and nuclear proteins were subjected to 10 or $14 \%$ SDS-PAGE, and electrophoretically transferred to nitrocellulose membrane. The membranes were incubated with specific primary antibodies, and subsequently incubated with secondary antibody conjugated with peroxidase (Bio-rad, Hercules, CA). The signal was detected using the chemiluminescent detection system (PIERCE) and quantified by using AlphaEaseFC (Alpha Innotech, FL).

\section{Inhibition of XPO1 expression by siRNA in PCa cells}

22Rv1 PCa cells were seeded in a 6 well plate $\left(3 \times 10^{5}\right.$ cells per well) and incubated at $37^{\circ} \mathrm{C}$ for 24 hours. The cells were then transfected with XPO1 siRNA (Santa Cruz) or control siRNA by DharmaFact Transfection Reagent (Dharmacon) for 72 hours. Then, 
the total RNA was extracted and subjected to mRNA RTqPCR for testing AR-v7, ARv567es, FOXA1, MED1, $\mathrm{UBE} 2 \mathrm{C}$ and XPO1 expression.

\section{Growth inhibition and isobologram assay}

22Rv1 and VCaP cells were treated with 50-200 nM selinexor, 5-20 $\mu \mathrm{M}$ enzalutamide, 5-20 $\mu \mathrm{M}$ abiraterone, or combination of selinexor with enzalutamide or abiraterone for 72 hours. Then, the cells were subjected to cell proliferation assay using MTT [3-(4,5-dimethylthiazol2-yl)-2,5-diphenyltetrazolium bromide]. The spectrophotometric absorbance of the samples was determined by using a plate reader SynergyHT (BioTek, Winooski, WI) at $570 \mathrm{~nm}$. The combination index (CI) value and isobologram were calculated and created by using CalcuSyn software (Biosoft, Cambridge, UK).

\section{Quantification of apoptosis by annexin V FITC assay}

Cell apoptosis was detected using Annexin V FITC (Biovision Danvers MA) according to the manufacturer's protocol as we reported previously [48]. PCa cells were treated with $300 \mathrm{nM}$ selinexor for $72 \mathrm{hrs}$. At the end of treatment, cells were trypsinized and equal numbers were stained with Annexin V and Propidum Iodide. The stained cells were analyzed using a Becton Dickinson flow cytometer at the Karmanos Cancer Institute Flow Cytometry Core.

\section{Animal studies}

The study was designed to evaluate the efficacy of selinexor (10 mg/kg, QoDx3/week) and KPT-8602 (15 mg/kg, QDx5/week) in a $22 \mathrm{Rv} 1$ prostate cancer xenograft model in CB.17 SCID mice. Mouse weights and tumor size were monitored three times a week. Each mouse was euthanized at the end of study (Day 35) or when tumor volume reached $1000 \mathrm{~mm}^{3}$, whichever comes first. Tumor were collected and fixed in $10 \%$ formalin for histopathology analysis.

The effects of combination treatment with KPT8602 and abiraterone was also evaluated in the 22Rv1 prostate cancer xenograft model in ICR-SCID mice. Six days after 22Rv1 transplantation, mice were randomized into 4 groups: Untreated $(n=5)$, abiraterone acetate treated $(n=5)$, KPT-8602 treated $(n=5)$ and combination treatment $(n=6)$. Abiraterone (Selleckchem) was administered orally each day at the dose of $100 \mathrm{mg} / \mathrm{kg}$ for 3 weeks. KPT-8602 was administered orally at $20 \mathrm{mg} / \mathrm{kg}$ twice a week for a total of 7 doses. All mice were followed for measurement of S.C. tumors and observed for changes in body weight and any side effects. All tumors were collected at 24 hours after last dose of combination treatment and tumor picture was taken.

\section{Immunostaining}

A tissue microarray (TMA) was constructed with tumor samples collected from 22Rv1 mouse prostate cancer model. Paraffin sections of the TMA were processed and stained with antibodies using a Biogenex I6000 automated stainer. Digital images of the slides were obtained through an Aperio AT Turbo scanner at 20×. The following antibodies were used for immunohistochemistry staining: Cleaved Caspase 3 (Cell Signaling Technology, 9661), p21 (Cell Signaling Technology, 2947), APC (Abcam, ab15270), Ki67 (Cell Marque, 275R-18), Rb (Abcam, ab181616), p53 (Santa Cruz, sc-126), SMAD4 (Santa Cruz, sc-7966), AR (Abcam, ab105225, and ARv (Abcam, ab198394).

\section{Statistics}

Wherever appropriate, the data were subjected to a Student's $t$-test using GraphPad Prism software (La Jolla, CA). $p<0.05$ was considered statistically significant.

\section{CONFLICTS OF INTEREST}

William Senapedis, Erkan Baloglu, Yosef Landesman, Michael Kauffman, Christian Argueta, Trinayan Kashyap, Hua Chang and Sharon Shacham are employees of Karyopharm Therapeutics and hold patents, equity and stocks and have received both major and minor remunerations from Karyopharm. All other authors have no potential conflict of interests.

\section{FUNDING}

Work in the lab of Azmi AS is supported by NIH 1R37CA215427-01A1.

\section{REFERENCES}

1. Siegel RL, Miller KD, Jemal A. Cancer Statistics, 2017. CA Cancer J Clin. 2017; 67:7-30.

2. Donovan MJ, Osman I, Khan FM, Vengrenyuk Y, Capodieci P, Koscuiszka M, Anand A, Cordon-Cardo C, Costa J, Scher HI. Androgen receptor expression is associated with prostate cancer-specific survival in castrate patients with metastatic disease. BJU Int. 2010; 105:462-67.

3. Sircar K, Yoshimoto M, Monzon FA, Koumakpayi IH, Katz RL, Khanna A, Alvarez K, Chen G, Darnel AD, Aprikian AG, Saad F, Bismar TA, Squire JA. PTEN genomic deletion is associated with p-Akt and AR signalling in poorer outcome, hormone refractory prostate cancer. J Pathol. 2009; 218:505-13.

4. de la Taille A, Rubin MA, Chen MW, Vacherot F, de Medina SG, Burchardt M, Buttyan R, Chopin D. Betacatenin-related anomalies in apoptosis-resistant and 
hormone-refractory prostate cancer cells. Clin Cancer Res. 2003; 9:1801-07.

5. Azoulay S, Terry S, Chimingqi M, Sirab N, Faucon H, Gil Diez de Medina S, Moutereau S, Maillé P, Soyeux P, Abbou C, Salomon L, Vacherot F, de La Taille A, et al. Comparative expression of Hedgehog ligands at different stages of prostate carcinoma progression. J Pathol. 2008; 216:460-70

6. Li Y, Hwang TH, Oseth LA, Hauge A, Vessella RL, Schmechel SC, Hirsch B, Beckman KB, Silverstein KA, Dehm SM. AR intragenic deletions linked to androgen receptor splice variant expression and activity in models of prostate cancer progression. Oncogene. 2012; 31:4759-67.

7. Sun S, Sprenger CC, Vessella RL, Haugk K, Soriano K, Mostaghel EA, Page ST, Coleman IM, Nguyen HM, Sun $\mathrm{H}$, Nelson PS, Plymate SR. Castration resistance in human prostate cancer is conferred by a frequently occurring androgen receptor splice variant. J Clin Invest. 2010; 120:2715-30.

8. Zhan Y, Zhang G, Wang X, Qi Y, Bai S, Li D, Ma T, Sartor O, Flemington EK, Zhang H, Lee P, Dong Y. Interplay between Cytoplasmic and Nuclear Androgen Receptor Splice Variants Mediates Castration Resistance. Mol Cancer Res. 2017; 15:59-68.

9. Zhang X, Morrissey C, Sun S, Ketchandji M, Nelson PS, True LD, Vakar-Lopez F, Vessella RL, Plymate SR. Androgen receptor variants occur frequently in castration resistant prostate cancer metastases. PLoS One. 2011; 6:e27970.

10. Cao S, Zhan Y, Dong Y. Emerging data on androgen receptor splice variants in prostate cancer. Endocr Relat Cancer. 2016; 23:T199-210.

11. Guo Z, Yang X, Sun F, Jiang R, Linn DE, Chen H, Chen H, Kong X, Melamed J, Tepper CG, Kung HJ, Brodie AM, Edwards J, Qiu Y. A novel androgen receptor splice variant is up-regulated during prostate cancer progression and promotes androgen depletion-resistant growth. Cancer Res. 2009; 69:2305-13.

12. Liu X, Ledet E, Li D, Dotiwala A, Steinberger A, Feibus A, Li J, Qi Y, Silberstein J, Lee B, Dong Y, Sartor O, Zhang H. A Whole Blood Assay for AR-V7 and ARv567es in Patients with Prostate Cancer. J Urol. 2016; 196:1758-63.

13. Lu J, Van der Steen T, Tindall DJ. Are androgen receptor variants a substitute for the full-length receptor? Nat Rev Urol. 2015; 12:137-44.

14. Gravina GL, Mancini A, Sanita P, Vitale F, Marampon F, Ventura L, Landesman Y, McCauley D, Kauffman M, Shacham S, Festuccia C. KPT-330, a potent and selective exportin-1 (XPO-1) inhibitor, shows antitumor effects modulating the expression of cyclin D1 and survivin [corrected] in prostate cancer models. BMC Cancer. 2015; 15:941.

15. Azmi AS, Aboukameel A, Bao B, Sarkar FH, Philip PA, Kauffman M, Shacham S, Mohammad RM. Selective inhibitors of nuclear export block pancreatic cancer cell proliferation and reduce tumor growth in mice. Gastroenterology. 2013; 144:447-56.

16. Ishizawa J, Kojima $\mathrm{K}$, Hail $\mathrm{N} \mathrm{Jr}$, Tabe $\mathrm{Y}$, Andreeff $\mathrm{M}$. Expression, function, and targeting of the nuclear exporter chromosome region maintenance 1 (CRM1) protein. Pharmacol Ther. 2015; 153:25-35.

17. Parikh K, Cang S, Sekhri A, Liu D. Selective inhibitors of nuclear export (SINE) - a novel class of anti-cancer agents. J Hematol Oncol. 2014; 7:78.

18. Gravina GL, Tortoreto M, Mancini A, Addis A, Di Cesare E, Lenzi A, Landesman Y, McCauley D, Kauffman M, Shacham S, Zaffaroni N, Festuccia C. XPO1/CRM1selective inhibitors of nuclear export (SINE) reduce tumor spreading and improve overall survival in preclinical models of prostate cancer (PCa). J Hematol Oncol. 2014; 7:46.

19. Mendonca J, Sharma A, Kim HS, Hammers H, Meeker A, De Marzo A, Carducci M, Kauffman M, Shacham S, Kachhap S. Selective inhibitors of nuclear export (SINE) as novel therapeutics for prostate cancer. Oncotarget. 2014; 5:6102-12. https://doi.org/10.18632/oncotarget.2174.

20. Wei XX, Siegel AP, Aggarwal R, Lin AM, Friedlander TW, Fong L, Kim W, Louttit M, Chang E, Zhang L, Ryan CJ. A Phase II Trial of Selinexor, an Oral Selective Inhibitor of Nuclear Export Compound, in Abiraterone- and/or Enzalutamide-Refractory Metastatic Castration-Resistant Prostate Cancer. Oncologist. 2018; 23:656-e64.

21. Liu G, Sprenger C, Wu PJ, Sun S, Uo T, Haugk K, Epilepsia KS, Plymate S. MED1 mediates androgen receptor splice variant induced gene expression in the absence of ligand. Oncotarget. 2015; 6:288-304. https://doi.org/10.18632/ oncotarget.2672.

22. Jones D, Wade M, Nakjang S, Chaytor L, Grey J, Robson $\mathrm{CN}$, Gaughan L. FOXA1 regulates androgen receptor variant activity in models of castrate-resistant prostate cancer. Oncotarget. 2015; 6:29782-94. https://doi. org/10.18632/oncotarget.4927.

23. $\mathrm{Hu} \mathrm{R}, \mathrm{Lu} \mathrm{C}$, Mostaghel EA, Yegnasubramanian S, Gurel M, Tannahill C, Edwards J, Isaacs WB, Nelson PS, Bluemn E, Plymate SR, Luo J. Distinct transcriptional programs mediated by the ligand-dependent full-length androgen receptor and its splice variants in castration-resistant prostate cancer. Cancer Res. 2012; 72:3457-62.

24. Peacock SO, Fahrenholtz CD, Burnstein KL. Vav3 enhances androgen receptor splice variant activity and is critical for castration-resistant prostate cancer growth and survival. Mol Endocrinol. 2012; 26:1967-79.

25. Stockley J, Markert E, Zhou Y, Robson CN, Elliott DJ, Lindberg J, Leung HY, Rajan P. The RNA-binding protein Sam68 regulates expression and transcription function of the androgen receptor splice variant AR-V7. Sci Rep. 2015; 5:13426.

26. Szafran AT, Stephan C, Bolt M, Mancini MG, Marcelli M, Mancini MA. High-Content Screening Identifies Src Family Kinases as Potential Regulators of AR-V7 Expression 
and Androgen-Independent Cell Growth. Prostate. 2017; 77:82-93.

27. Sonenberg N. eIF4E, the mRNA cap-binding protein: from basic discovery to translational research. Biochem Cell Biol. 2008; 86:178-83.

28. Strudwick S, Borden KL. The emerging roles of translation factor eIF4E in the nucleus. Differentiation. 2002; 70:10-22.

29. van der Watt PJ, Maske CP, Hendricks DT, Parker MI, Denny L, Govender D, Birrer MJ, Leaner VD. The Karyopherin proteins, Crm 1 and Karyopherin beta1, are overexpressed in cervical cancer and are critical for cancer cell survival and proliferation. Int J Cancer. 2009; 124:1829-40.

30. Noske A, Weichert W, Niesporek S, Röske A, Buckendahl AC, Koch I, Sehouli J, Dietel M, Denkert C. Expression of the nuclear export protein chromosomal region maintenance/exportin $1 / \mathrm{Xpo} 1$ is a prognostic factor in human ovarian cancer. Cancer. 2008; 112:1733-43.

31. Yao Y, Dong Y, Lin F, Zhao H, Shen Z, Chen P, Sun YJ, Tang LN, Zheng SE. The expression of CRM1 is associated with prognosis in human osteosarcoma. Oncol Rep. 2009; 21:229-35.

32. Shen A, Wang Y, Zhao Y, Zou L, Sun L, Cheng C. Expression of CRM1 in human gliomas and its significance in p27 expression and clinical prognosis. Neurosurgery. 2009; 65:153-59.

33. Huang WY, Yue L, Qiu WS, Wang LW, Zhou XH, Sun YJ. Prognostic value of CRM1 in pancreas cancer. Clin Invest Med. 2009; 32:E315.

34. Zhou F, Qiu W, Yao R, Xiang J, Sun X, Liu S, Lv J, Yue L. CRM1 is a novel independent prognostic factor for the poor prognosis of gastric carcinomas. Med Oncol. 2013; 30:726.

35. Tai YT, Landesman Y, Acharya C, Calle Y, Zhong MY, Cea M, Tannenbaum D, Cagnetta A, Reagan M, Munshi AA, Senapedis W, Saint-Martin JR, Kashyap T, et al. CRM1 inhibition induces tumor cell cytotoxicity and impairs osteoclastogenesis in multiple myeloma: molecular mechanisms and therapeutic implications. Leukemia. 2014; 28:155-65.

36. Kojima K, Kornblau SM, Ruvolo V, Dilip A, Duvvuri S, Davis RE, Zhang M, Wang Z, Coombes KR, Zhang N, Qiu YH, Burks JK, Kantarjian H, et al. Prognostic impact and targeting of CRM1 in acute myeloid leukemia. Blood. 2013; 121:4166-74.

37. Kuruvilla J, Savona M, Baz R, Mau-Sorensen PM, Gabrail N, Garzon R, Stone R, Wang M, Savoie L, Martin P, Flinn I, Jacoby M, Unger TJ, et al. Selective inhibition of nuclear export with selinexor in patients with non-Hodgkin lymphoma. Blood. 2017; 129:3175-83.
38. Conforti F, Wang Y, Rodriguez JA, Alberobello AT, Zhang YW, Giaccone G. Molecular Pathways: Anticancer Activity by Inhibition of Nucleocytoplasmic Shuttling. Clin Cancer Res. 2015; 21:4508-13.

39. Tan DS, Bedard PL, Kuruvilla J, Siu LL, Razak AR. Promising SINEs for embargoing nuclear-cytoplasmic export as an anticancer strategy. Cancer Discov. 2014; 4:527-37.

40. Scheper GC, Proud CG. Does phosphorylation of the capbinding protein eIF4E play a role in translation initiation? Eur J Biochem. 2002; 269:5350-59.

41. Cinar B, De Benedetti A, Freeman MR. Post-transcriptional regulation of the androgen receptor by Mammalian target of rapamycin. Cancer Res. 2005; 65:2547-53.

42. Yin L, Hu Q. CYP17 inhibitors - abiraterone, C17,20-lyase inhibitors and multi-targeting agents. Nat Rev Urol. 2014; 11:32-42.

43. Rodriguez-Vida A, Galazi M, Rudman S, Chowdhury S, Sternberg CN. Enzalutamide for the treatment of metastatic castration-resistant prostate cancer. Drug Des Devel Ther. 2015; 9:3325-39.

44. Tran C, Ouk S, Clegg NJ, Chen Y, Watson PA, Arora V, Wongvipat J, Smith-Jones PM, Yoo D, Kwon A, Wasielewska T, Welsbie D, Chen CD, et al. Development of a second-generation antiandrogen for treatment of advanced prostate cancer. Science. 2009; 324:787-90.

45. Crona DJ, Milowsky MI, Whang YE. Androgen receptor targeting drugs in castration-resistant prostate cancer and mechanisms of resistance. Clin Pharmacol Ther. 2015; 98:582-89.

46. Efstathiou E, Titus M, Wen S, Hoang A, Karlou M, Ashe R, Tu SM, Aparicio A, Troncoso P, Mohler J, Logothetis CJ. Molecular characterization of enzalutamide-treated bone metastatic castration-resistant prostate cancer. Eur Urol. $2015 ; 67: 53-60$.

47. Neggers JE, Vercruysse T, Jacquemyn M, Vanstreels E, Baloglu E, Shacham S, Crochiere M, Landesman Y, Daelemans D. Identifying drug-target selectivity of smallmolecule CRM1/XPO1 inhibitors by CRISPR/Cas9 genome editing. Chem Biol. 2015; 22:107-16.

48. Aboukameel A, Muqbil I, Senapedis W, Baloglu E, Landesman Y, Shacham S, Kauffman M, Philip PA, Mohammad RM, Azmi AS. Novel p21-Activated Kinase 4 (PAK4) Allosteric Modulators Overcome Drug Resistance and Stemness in Pancreatic Ductal Adenocarcinoma. Mol Cancer Ther. 2017; 16:76-87. 